\title{
Compliance with epidemic-prone diseases surveillance and response guidelines among health officers at surveillance units in South-West Nigeria
}

\author{
Magbagbeola David Dairo, Daniel Ola Afolayan, Joshua Odunayo Akinyemi
}

Department of Epidemiology and Medical Statistics, Faculty of Public Health, College of Medicine, University of Ibadan, Ibadan, Oyo State, Nigeria.

\begin{abstract}
Introduction: Although compliance with surveillance guidelines is crucial to epidemic diseases control, determinants of use of these guidelines in Nigeria are poorly documented. We assess health workers compliance and factors associated with the surveillance and response guidelines for epidemic-prone diseases in South-West Nigeria.

Methods: In a cross-sectional study, 199 disease surveillance and notification officers in Oyo state were interviewed using a questionnaire on knowledge of disease surveillance and performance of surveillance activities. Data were analysed using descriptive statistics, chi-square and multiple logistic regression at $\mathrm{P}=0.05$.

Results: Most surveillance units submitted disease outbreaks reports $(81.48 \%$ at the health facility and $100 \%$ at the local government level). Timeliness and completeness of weekly reporting were $94 \%$ and $95 \%$ respectively. a quarter $(25.9 \%)$ adhered to national case definitions guidelines. About $85.7 \%$ did laboratory case confirmation while $2.6 \%$ did facility level data analysis. Predictors for six months reporting activity include attending a training on surveillance and reporting $(\mathrm{OR}=7.92$; $\mathrm{CI}=1.65-37.92)$, fund adequacy $(\mathrm{OR}=27.81 ; \mathrm{CI}=7.68-100.60)$ and knowledge of surveillance dataflow $(\mathrm{OR}=4.80 ; \mathrm{CI}=1.64-14.10)$.

Conclusion: In addition to provision of adequate financial and laboratory resources, surveillance activities would benefit from continuous training on surveillance data flow.

Keywords: Epidemic-prone diseases, case definitions guidelines, surveillance and response.

DOI: https://dx.doi.org/10.4314/ahs.v18i2.28

Cite as: Dairo MD, Afolayan DO, Akinyemi JO. Compliance with epidemic-prone diseases surveillance and response guidelines among health officers at surveillance units in South-West Nigeria. Afri Health Sci. 2018;18(2): 428-436. bttps:/ / dx.doi.org/10.4314/abs.v18i2.28
\end{abstract}

\section{Introduction}

The prevention, control and reduction of mortality from epidemics are dependent on an effective disease surveillance system. ${ }^{1,2}$ The National Technical Guideline for Integrated Disease Surveillance and Response (IDSR) seeks to ensure the performance of core surveillance activities at all surveillance units (health facilities, local government health departments, states and national epidemiology
Corresponding author:
Magbagbeola David Dairo,
Department of Epidemiology
and Medical Statistics,
University of Ibadan, Ibadan, Oyo State
Telephone: (+234) 8035664708
Email: drdairo@yahoo.com

unit). ${ }^{3}$ The guideline specifies the core activities of infectious disease surveillance and response system to include: detection, confirmation and registration of cases of diseases; disease reporting; data analysis and interpretation; feedback; epidemic preparedness and responses to outbreaks. ${ }^{3,4}$ It also specifies that health authorities should provide support for the surveillance and response system such as standard guidelines, reporting forms, training, funding, supervision, logistic resources. ${ }^{3}$

Epidemic-prone diseases (EPD) in Nigeria include cholera, cerebrospinal meningitis, diarrhoea with blood (shigella), measles, yellow fever, viral hemorrhagic fevers (such as lassa fever) and highly pathogenic avian influen$\mathrm{za}^{3}$ These diseases keep occurring and cause the highest case fatality rate in Nigeria. ${ }^{5}$ Nigeria has been faced with repeated out-breaks of these epidemic-prone diseases in recent years. ${ }^{6-10}$ Meanwhile, the surveillance of these

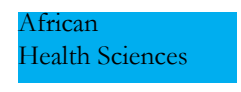

(C) 2018 Dairo et al. Licensee African Health Sciences. This is an Open Access article distributed under the terms of the Creative commons Attribution License (https://creativecommons.org/licenses/by/4.0), which permits unrestricted use, distribution, and reproduction in any medium, provided the original work is properly cited. 
diseases has been recognized to be weak in Nigeria.,10-14 This study aims to assess compliance with the surveillance and response guidelines for epidemic-prone diseases in South-West Nigeria.

\section{Methods}

Study design: A cross sectional descriptive study of the surveillance workers for epidemic prone diseases (EPD) at surveillance units was conducted.

\section{Study population:}

The study population was the disease surveillance and notification officers throughout Oyo State. This population includes the state epidemiologist at the state Ministry of Health. At the local government level the population included disease surveillance and notification officers. At the health facility level, the population of disease surveillance officers included the health workers (focal persons) who were assigned the responsibility of reporting on the disease patterns and out-breaks that occurred at the health facility and reporting of out-breaks of diseases within the catchment areas of their health facility.

\section{Sample size determination}

The minimum sample size for the study was derived using the formula for a simple descriptive cross-sectional study as follows:

$$
\mathrm{n}=\mathrm{z}^{2} \mathrm{pq} / \mathrm{d}^{2}
$$

where $\quad \mathrm{n}=$ calculated sample size,

$\mathrm{z}=$ standard normal deviate at $95 \%$ confidence

interval=1.96,

$\mathrm{p}=$ proportion of Disease Surveillance and Notification

Officers that regularly report surveillance data to the state epidemiology unit $=0.858,1$

$\mathrm{q}=1-\mathrm{p}$, and $\mathrm{d}=5 \%$ precision of the estimate of the sample size.

After substitution of the relevant figures a sample size of $n=188$ surveillance officers was obtained. A projected non-response rate of $5 \%$ was then included to derive a minimum sample size of 198 surveillance officers.

\section{Sampling procedure}

A four stage sampling was used for selecting the respondents. In the first stage, Oyo state was randomly selected by simple balloting from the list of the six states in SouthWest Nigeria. The states in South-West Nigeria are Ekiti, Lagos, Ogun, Osun, Ondo and Oyo states.

In the second stage, three local government areas were randomly selected by balloting from the sample frame of local governments in each of the three senatorial districts (North, Central and South) in Oyo state. After the balloting the following local government areas were selected; Kajola, Ogbomosho south, and Surulere Local government areas were chosen from Oyo North Senatorial district; Afijio, Akinyele, and Egbeda Local government areas from Oyo Central Senatorial district while Ibadan North, Ibadan SouthEast and Ibarapa East Local governments areas were selected from Oyo South Senatorial district.

In the third stage, seven wards each were randomly selected by balloting from the list of the health wards in each of the local government areas. In the fourth stage, three health facilities were randomly selected by balloting from each of the wards. Only the consenting health workers who are assigned the duty of reporting diseases occurrence in the health facilities were interviewed. This study interviewed a total of 199 officers at various levels of surveillance activities in the state as follows. Thus the respondents interviewed are drawn from the units of surveillance as follows; the State epidemiology unit $(\mathrm{n}=1)$ represented by the State epidemiologist, the local gove rnment health departments $(n=9)$ represented by the disease surveillance and notification officers (DSNO) and at the health facilities $(n=189)$ represented by the focal persons.

\section{Data collection instrument}

Data was obtained by the use of questionnaires, checklists, and records review of the monthly and weekly reporting surveillance data from surveillance units at the Oyo state Ministry of Health and the local government health department.

The questionnaires were derived from the review of the literature on the subject matter and sought information on socio-demographics of the respondents, knowledge on disease surveillance by the officers at the surveillance units. The questionnaire was self administered since all the participants in the study could read and write in English.

Meanwhile, a checklist was used to obtain information on performance of core surveillance activities and support functions. The checklist was used to review the health facility out-patient register, log books and copies of laboratory reports at health facilities, copies of completed IDSR forms, tables or charts showing analysis of EPD, 
and also to ascertain the availability of standard case definition poster and logistic resources at the surveillance units.

Timelines and completeness of weekly reports in the selected local government areas for the year were obtained from the Epidemiology Unit of the Ministry of Health, Oyo state. Timeliness of reporting was defined as the submission of surveillance reports on or before the stipulated time for submission which is specified by the epidemiology unit of the state. Completeness of reporting was defined as the proportion of expected reports that were received at the end of the cut-off date. ${ }^{15}$

Epidemic preparedness was assessed by determining the presence of an Epidemic Preparedness and Response (EPR) team, Epidemic Management Committee (EMC), written EPR plans, availability of stocks of drugs and ma- terial supplies for out-break response at the State epidemiology unit and local government health departments. Data were analysed using descriptive statistics, chi-square and multiple logistic regression at $\mathrm{P}=0.05$ on SPSS ver$\operatorname{sion}^{20}$.

\section{Ethical approval}

Ethical approval for the study was obtained from the Oyo State Ethical Review Committee. The confidentiality of the respondents was assured. The respondents were informed of their freedom of refusal to participate in the study. The study was conducted in accordance with the Helsinki Declaration of 1975, as revised in 2000.

\section{Results}

About half of the surveillance workers were trained on disease surveillance. (Table 1)

\section{Table 1: Socio-demographic characteristics of study respondents at epidemiological units}

\begin{tabular}{|c|c|c|}
\hline $\begin{array}{l}\text { Characteristics } \\
\text { Age }\end{array}$ & $N=199$ & $\%$ \\
\hline $20-29$ years & 34 & 17 \\
\hline $30-39$ years & 69 & 34.7 \\
\hline $40-49$ years & 46 & 23.1 \\
\hline 50 years and above & 50 & 25.1 \\
\hline \multicolumn{3}{|l|}{ Gender } \\
\hline Males & 69 & 34.7 \\
\hline Females & 130 & 65.3 \\
\hline \multicolumn{3}{|l|}{ Marital status } \\
\hline Married & 159 & 79.9 \\
\hline Single/Others & 40 & 20.1 \\
\hline \multicolumn{3}{|l|}{ Occupation (cadre) } \\
\hline Nurses & 109 & 54.8 \\
\hline Medical Records officers & 41 & 20.6 \\
\hline Doctors & 37 & 18.6 \\
\hline Laboratory scientist & 2 & 1.0 \\
\hline Others $^{*}$ & 10 & 5.0 \\
\hline \multicolumn{3}{|l|}{ Length of service } \\
\hline $1-5$ years & 26 & 13.1 \\
\hline $6-10$ years & 55 & 27.6 \\
\hline 11-20years & 55 & 27.6 \\
\hline $21-30$ years & 63 & 31.7 \\
\hline \multicolumn{3}{|l|}{ Type of Surveillance unit } \\
\hline State epidemiology unit & 1 & 0.5 \\
\hline Local government health department & 9 & 4.5 \\
\hline Primary health care centre & 94 & 47.3 \\
\hline Private health facility & 91 & 45.7 \\
\hline Secondary health care centre & 4 & 2.0 \\
\hline Tertiary health care centre & 0 & 0.0 \\
\hline \multicolumn{3}{|l|}{ Training on disease surveillance } \\
\hline Trained & 98 & 49.2 \\
\hline Not trained & 101 & 50.8 \\
\hline
\end{tabular}


Disease reporting was carried out by 154 (81.48\%) surveillance units at the health facility level and all surveillance units at the local government health department level. However, in the period of six months preceeding the survey, only about three-quarter regularly submitted monthly surveillance data report.(Table 2) Reporting timeliness for weekly surveillance data was high (94\%) while completeness was also high (95\%). The State epidemiology unit regularly submitted monthly and weekly surveillance data to the Federal epidemiology unit, provided feedback to all the DSNO's, analysed data for EPD, and epidemic preparedness was good.

Table 2: Compliance with epidemic-prone disease surveillance and response guidelines at health facilities and Local government health departments

\begin{tabular}{|c|c|c|c|c|}
\hline \multirow[t]{2}{*}{ Guidelines } & \multicolumn{2}{|c|}{ Health facilities } & \multicolumn{2}{|c|}{$\begin{array}{c}\text { Local government health } \\
\text { departments }\end{array}$} \\
\hline & $(n=189)$ & $\%$ & $(n=9)$ & $\%$ \\
\hline \multicolumn{5}{|l|}{ Case Identification } \\
\hline Utilise Standard case definition & 49 & 25.9 & $N A^{*}$ & - \\
\hline $\begin{array}{l}\text { Case confirmation } \\
\text { Utilize laboratory confirmation }\end{array}$ & 162 & 85.7 & NA & - \\
\hline \multicolumn{5}{|l|}{ Case registration } \\
\hline Register cases & 180 & 95.2 & NA & - \\
\hline \multicolumn{5}{|l|}{ Disease Reporting } \\
\hline $\begin{array}{l}\text { Submit regular monthly report } \\
\text { (in the past 6months) }\end{array}$ & 144 & 76.2 & 9 & 100 \\
\hline Have a reporting practice & 154 & 81.4 & 9 & 100 \\
\hline $\begin{array}{l}\text { Feedback } \\
\text { Provide feedback to health } \\
\text { facilities submitting report } \\
\text { Analyse EPD data }\end{array}$ & $\mathrm{NI}^{* *}$ & $\mathrm{NI}$ & 9 & 100 \\
\hline $\begin{array}{l}\text { Analyse data within health } \\
\text { facility } \\
\text { Epidemic preparedness \& } \\
\text { response }\end{array}$ & 5 & 2.6 & 7 & $77.8 \%$ \\
\hline Presence of EPR team & NA & & 9 & 100 \\
\hline Presence of EMC & NA & - & 0 & 0 \\
\hline Written EPR plan & NA & - & 0 & 0 \\
\hline Stocks of drugs & NA & - & 0 & 0 \\
\hline Stocks of material supplies & NA & - & 9 & 100 \\
\hline
\end{tabular}

= Not Applicable

$\stackrel{* *}{*}$ No Information

Less than half of the surveillance workers had received supervisory visit $(35.7 \%)$ and feedback (45.7\%) from higher health authorities. At the health facility level, $25.9 \%$ adhered to case definitions guidelines as specified in the national guideline. About $85.7 \%$ used laboratory findings for case confirmation, and $2.6 \%$ performed analysis of the collected surveillance data at their health facility level before submission to state health department. Meanwhile, less than two-thirds (62.3\%) of the surveillance workers reported that funds for surveillance activities were adequate.(Table 3) 
Table 3: Surveillance support functions available to the surveillance worker at surveillance units

\begin{tabular}{|c|c|c|c|}
\hline Support functions & Available & Inadequate & Not Available \\
\hline $\begin{array}{c}\text { Knowledge on pathway } \\
\text { of dataflow }\end{array}$ & $110(55.3 \%)$ & & $89(44.7 \%)$ \\
\hline Standard case definition & $62(31.2 \%)$ & - & $137(68.8 \%)$ \\
\hline \multicolumn{4}{|l|}{ Supervision visit } \\
\hline (From higher health authorities) & $71(35.7 \%)$ & - & $128(64.3 \%)$ \\
\hline \multicolumn{4}{|l|}{ Feedback } \\
\hline (From higher health authorities) & $91(45.7 \%)$ & - & $108(54.3 \%)$ \\
\hline \multicolumn{4}{|l|}{ Logistic resources available } \\
\hline IDSR Form (003) & $69(34.7 \%)$ & - & $130(65.3 \%)$ \\
\hline Adequate stationery & $171(85.9 \%)$ & $25(12.6 \%)$ & $3(1.5 \%)$ \\
\hline Motor vehicle & $133(66.8 \%)$ & - & $66(33.2 \%)$ \\
\hline Computer & $82(41.2 \%)$ & - & $117(58.8 \%)$ \\
\hline Printer & $41(20.6 \%)$ & - & $158(79.4 \%)$ \\
\hline Generator & $169(84.9 \%)$ & - & $30(15.1 \%)$ \\
\hline Telephone & $195(98.0 \%)$ & - & $4(2.0 \%)$ \\
\hline Calculator & $176(88.4 \%)$ & - & $23(11.6 \%)$ \\
\hline Adequacy of funding & $124(62.3 \%)$ & $37(18.6 \%)$ & $38(19.10 \%)$ \\
\hline
\end{tabular}

Predictors for compliance (regular adherence) with (OR=27.81; CI=7.68-100.60), knowledge on pathway of monthly reporting guideline for 6 months were train- data flow $(\mathrm{OR}=4.80 ; \mathrm{CI}=1.64-14.10)$, and 21-30 years of ing $(\mathrm{OR}=7.92 ; \mathrm{CI}=1.65-37.92)$, adequacy of funds service $(\mathrm{OR}=6.41 ; \mathrm{CI}=1.36-30.31)$. (Table 4) 
Table 4: Predictors for 6 months reporting compliance at surveillance units

\begin{tabular}{|c|c|c|c|c|}
\hline Variable & Categories & OR & 95\% C.I & p-value \\
\hline Marital status & $\begin{array}{l}\text { Others" } \\
\text { Married }\end{array}$ & $\begin{array}{l}\text { Ref } \\
1.889\end{array}$ & $0.361-9.990$ & 0.452 \\
\hline Length of service & $\begin{array}{l}1-10 \text { years } \\
11-20 \text { years } \\
21-30 \text { years }\end{array}$ & $\begin{array}{l}\text { Ref } \\
1.185 \\
6.412\end{array}$ & $\begin{array}{l}0.333-4.223 \\
1.357-30.309\end{array}$ & $\begin{array}{l}0.793 \\
0.019^{*}\end{array}$ \\
\hline $\begin{array}{l}\text { knowledge on pathway } \\
\text { of dataflow }\end{array}$ & $\begin{array}{l}\text { No } \\
\text { Yes }\end{array}$ & $\begin{array}{l}\text { Ref } \\
4.804\end{array}$ & $1.636-14.104$ & $0.004^{*}$ \\
\hline Reporting form (IDSR 003) & $\begin{array}{l}\text { Available } \\
\text { Not available }\end{array}$ & $\begin{array}{l}\text { Ref } \\
1.211\end{array}$ & $0.172-8.506$ & 0.847 \\
\hline $\begin{array}{l}\text { Received Training } \\
\text { (on disease surveillance) }\end{array}$ & $\begin{array}{l}\text { No } \\
\text { Yes }\end{array}$ & $\begin{array}{l}\text { Ref } \\
7.917\end{array}$ & $1.653-37.919$ & $0.010^{*}$ \\
\hline $\begin{array}{l}\text { Receive Supervision } \\
\text { (from higher health authorities) }\end{array}$ & $\begin{array}{l}\text { Yes } \\
\text { No }\end{array}$ & $\begin{array}{l}\text { Ref } \\
1.500\end{array}$ & $0.361-6.226$ & 0.577 \\
\hline $\begin{array}{l}\text { Receive Feedback } \\
\text { (from higher health authorities) }\end{array}$ & $\begin{array}{l}\text { No } \\
\text { Yes }\end{array}$ & $\begin{array}{l}\text { Ref } \\
1.357\end{array}$ & $0.381-4.825$ & 0.637 \\
\hline Motor vehicle & $\begin{array}{l}\text { Not available } \\
\text { Available }\end{array}$ & $\begin{array}{l}\text { Ref } \\
1.119\end{array}$ & $0.386-3.245$ & 0.836 \\
\hline Stationery & $\begin{array}{l}\text { Inadequate } \\
\text { Adequate }\end{array}$ & $\begin{array}{l}\text { Ref } \\
5.325\end{array}$ & $0.952-29.777$ & 0.057 \\
\hline Funds & $\begin{array}{l}\text { Inadequate } \\
\text { Adequate }\end{array}$ & $\begin{array}{l}\text { Ref } \\
27.805\end{array}$ & $7.683-100.6$ & $<0.001^{*}$ \\
\hline
\end{tabular}

**=single/widowed

${ }^{*}=$ statistically significant

\section{Discussion}

Compliance with the EPD surveillance and response guidelines was higher at the State and local government level than at health facilities. This was similar to what was obtainable in other African countries. ${ }^{16,17}$ Compliance with Epidemic Prone Diseases surveillance guidelines on the utilisation of standard case definition was found in only about a quarter of the health facilities; which was lower than the findings in the 2009 report on integrated disease surveillance and response (IDSR) in Nigeria in which only a third of the health facilities had available in the health facility standard case definitions posters for any priority disease. ${ }^{18}$ These differences are perhaps due to differences in methodology of assessing the compliance with the guidelines. In the Kaduna study; the compliance with epidemic prone diseases was assessed based on the presence of a poster on each of the epidemic prone diseases within the health facility. In this current study, compliance to the guidelines was based on reported use of the guidelines by the staff of the health facility. It is expected that presence of a poster showing the guidelines does not necessarily translate to its use by the health officers, hence the lower compliance rate found in this study.

In this study, also almost half of the surveillance units had no standard case definition posters. The findings in our study were similar to what was reported in Tanzania which revealed that provisions of standard case definition guidelines to health facilities were insufficient. ${ }^{19}$ These findings were further corroborated by other studies in Tanzania and previously in Nigeria, which found that majority of the health facilities do not have any case defini- 
tion poster or booklet for any of the priority diseases. ${ }^{15,20}$ Although a high percentage (about four-fifth) of the respondents claimed to resort to laboratory investigation for confirmation of cases of epidemic prone diseases, this finding still indicates a gap in the laboratory support for surveillance at the local level. This finding, however is in contrast to the report of Sahal et al in Khartoum state of Sudan which reported that all health facilities had a functioning laboratory. ${ }^{16}$

Registration of cases in clinic registers in this study was similar to the findings in Uganda which revealed that 92\% of health facilities had clinic registers. ${ }^{21}$ Sahal in Sudan had also reported that all health facilities in Sudan had clinic registers. ${ }^{16}$ Furthermore Sow et al also showed that clinical registers were available in more than $95 \%$ of all health facilities in Cape Verde ${ }^{17}$. Thus the similarity observed in this study is probably due to the fact that registration and diagnosis are routine practices in all health facilities.

The submission of disease reporting data by the surveillance officers was found to be very high $(81.5 \%)$ in this study. Lower rates of submission were found in studies in other parts of Nigeria. In the Northern parts of Nigeria, a study in Kaduna state reported that only $57 \%$ submitted their surveillance reports to the state ministry of health within 6 moinths of the survey. In Yobe, another Northern state of Nigeria, $70.9 \%$ of the surveillance officers submitted their reports to the state office within 6 months of collection. ${ }^{22,23}$ These two states are in the Northern part of the country and were known to have shortfalls in employment of medically qualified officers of health. Thus these differences observed could be due to the employment of medical officers of health in all the local government health departments in Oyo State. The medical officers of health were all postgraduate degree holders in Public Health and had the statutory duties to ensure mandatory reporting of notifiable diseases.

However, compliance with regular weekly reporting of EPD over six months period was high (about four-fifths) among the surveillance officers and was similar to the findings of Dairo et al, on weekly reporting in both Ekiti and Osun states. ${ }^{1}$ Both of these states are also South Western Nigeria states, that had also adopted medical officers of health supervision of the process of reporting notifiable diseases in their territories. The high rate of completeness of weekly reporting (95\%) found in this study is similar to $92 \%$ found among the surveillance officers in health districts of eight selected African countries (Cape Verde, Eritrea, Ethiopia, Lesotho, Gambia, Guinea-Bissau, Malawi and Uganda). ${ }^{17}$

Meanwhile, the timeliness of reporting in this study was found to be very high $(94.5 \%)$. This is in contrast to the $47 \%$ timeliness of reporting found among surveillance officers in the health districts in Tanzania and higher than the $85 \%$ reported among the surveillance officers in health districts of other eight selected African countries (Cape Verde, Eritrea, Ethiopia, Lesotho, Gambia, Guinea-Bissau, Malawi and Uganda). ${ }^{15,17}$ The reported differences could be attributed to the financial support to the surveillance officers in Oyo State by the World Health organization to ensure zero reporting strategy. Thus all disease surveillance officers and focal persons are motivated to comply. Thus the timeliness of reporting in Oyo State is commendable as it exceeds the WHO/CDC target of $80 \%$ of all facilities.

Only five $(2.6 \%)$ health facilities analysed surveillance data for any of the epidemic-prone diseases and 46 (24.3\%) analysed for at least only malaria. This percentage of surveillance officers engaged in local analysis of data in their facilities is higher than the findings in Kaduna state which reported that only $19 \%$ of them did any form of data analysis in their health facilities. ${ }^{22}$ This proportion is also higher than the 10\% reported in Uganda but lower than the $32 \%$ reported by Mghamba in Tanzania. ${ }^{19,21}$ In addition Gueye et al in Tanzania also reported that 33\% of health workers in the facilities surveyed did data analysis for priority diseases while $28 \%$ did for malaria. ${ }^{15}$ The lack of data analysis at the health facility level could be due to the fact that health workers consider the data collected as just required for forwarding to higher levels rather than for local use. At the local levels, health workers should be able to make tables of frequencies of diseases occurrence and draw graphs of trend of their occurrence.

Although the IDSR criteria on epidemic preparedness and response were met by the State epidemiology unit in this study, epidemic preparedness among the Local governments area health facilities was completely absent. This observation is similar to the finding reported in Sabon Gari Local government area of Kaduna state where 
epidemic preparedness was poor as less than half of the epidemic preparedness and response criteria were met. ${ }^{24}$ In our study there were no stocks of drugs and materials such as specimen bottles, needles and syringes for outbreak response. This is despite the indication that the local government health departments had standby emergency response team. The lack of emergency preparedness despite availability of emergency response team indicates a disconnection that will delay or hinder the implementation of any emergency response plan.

This study revealed that training of surveillance workers was a predictor for compliance with EPD monthly reporting guideline over six months. Participation in training for surveillance was reported by almost half of the respondents at the health facility level and all the disease surveillance and notification officers at the local government levels. . The salutary effect of training on performance of surveillance functions had been reported in a study by Bawa and Olumide in Yobe state that showed that training positively impacts the disease notification habits of health personnel. ${ }^{25}$

Adequacy of funds, which was found to be a predictor for compliance with EPD monthly reporting guideline is in agreement with the report of a study in Osun and Ekiti state which showed that adequate funding was a predictor for the reporting of out-breaks. ${ }^{1}$

The observation in this study that knowledge of the surveillance dataflow pathway among surveillance workers is a predictor for compliance with the EPD reporting guideline corroborates the findings in Ekiti and Osun state in which it was reported that the knowledge of the pathway of disease notification directs surveillance workers and indirectly predicts the level of awareness of their duty. ${ }^{1}$ This finding also agrees with another study by Sow et al that reports that district health personnel knowledge about the national priority diseases improves reporting completeness and timeliness. ${ }^{17}$

The 21-30 years of service as a predictor for compliance with EPD reporting guideline may probably be due to the fact that these workers might have been exposed to training on disease surveillance during their long length of service. Furthermore increased years of service would enable understanding of roles and responsibilities and development of necessary skills required for the performance of statutory duties. These officers would also have been given leadership and supervisory roles that compels the performance of their duties in a satisfactory manner.

\section{Conclusion}

Compliance with the core surveillance guidelines is good at the state level. However, it is defective at the local government health departments (with respect to poor epidemic preparedness) and at the health facilities (with respect to the utilisation of standard case definitions and health facility based analysis of EPD surveillance data). Furthermore this study reveals the inadequacy of laboratory support for surveillance activities at the local levels. It is recommended that local and State government ensure the provision of continuous training and resources to surveillance workers so as to achieve effective disease control. The strengthening of laboratory support for disease surveillance at the local health facility level has also become imperative.

\section{Acknowledgement}

We acknowledge the support of Dr. Gbolahan Abass who was the State Epidemiologist for his technical help during the study.

\section{Conflict of interest}

We declare no conflict of interest in this article.

\section{References}

1. Dairo MD, Bamidele JO, and Adebimpe WO. Disease surveillance and reporting in two Southwestern states in Nigeria: Logistic challenges and prospects. Journal of Public Health and Epidemiology. 2010; 2(6):125-129

2. World Health Organization (WHO). WHO Report on Global Surveillance of Epidemic-prone Infectious Diseases. WHO/CDS/CSR/ISR/2000.1

3. Federal Ministry of Health (Nigeria). National Technical Guidelines on Integrated Disease Surveillance and Response 2009; Abuja, Nigeria.

4. Nsubuga P, Eseko N, Tadesse W, Ndayimirije N, Stella $\mathrm{C}$, and McNabb S. Structure and performance of infectious disease surveillance and response. Bull World Health Organ. 2000; 80(3):196-203.

5. Federal Ministry of Health (Nigeria). National Guidelines on Integrated Disease Surveillance and Response, 2006; Abuja, Nigeria.

6. Adedire E, Gbolahan A, Nguku P, Usman A, Ogunniyi 
O, Gbadegesia Y. Outbreak of Lassa fever in a bakery: investigation and epidemiological surveillance of contact persons, Ibadan Oyo state, Southwestern Nigeria. Poster presented at the 16th International Congress on Infectious disease 2014; Cape Town, South Africa.

7. Falade G, Lagunju IA, Bakare RA, Odekanmi AA, Adegbola RA. Invasive Pneumococcal Disease in Children Aged < 5 Years Admitted to 3 Urban Hospitals in Ibadan, Nigeria. Clinical Infectious Diseases. 2009; 48(2):190_ 6

8. Gbolahan AO, Abass WA, Adewuyi P, Olawoyin OB. Spatial analysis of cholera outbreak in Egbeda local government area of Oyo state. International Journal of Infectious Disease. 2013; 21(1):254

9. Ogunniyi A, Poggensse G, Fasina A, Nguku P. Cholera outbreaks in Ibadan, Oyo State, Nigeria: Identification of circulating strain and its with antimicrobial susceptibility pattern. Poster presentation at the $20^{\text {th }}$ IEA World Congress of Epidemiology 2013; Alaska, U.S.A

10. Onoja AB, Adeniji AJ, Faneye A. Measles complications in a Nigerian hospital setting. Clinical Reviews and Opinions. 2013; 5(2):18-23

11. Adagbada AO, Adesida SA, Nwaokorie FO, Niemogha MT, Coker AO. Cholera epidemiology in Nigeria: an overview. Pan African Medical Journal. 2012; 12(59): 3540

12. Fatiregun AA, Sangowawa AO, Abubakar OA. Outcome of training on yellow fever surveillance in a South-western state, Nigeria: implications for improved Field implementation. Nigerian Journal of Clinical Practice. 2010; 13(4):449-452.

13. Ofili AN, Ugwu EN, Zirebe A, Richards R, Salami S. Knowledge of disease notification among doctors in government hospitals in Benin City, Edo State, Nigeria. Public Health 2003; 117(3):214-217. PubMed

14. Olowookere S, Fatiregun A, Gbolahan O, Adepoju G. Diagnostic proficiency and reporting of Lassa fever by Nigerian physicians in Osun State of Nigeria. BMC Infectious Diseases. 2014; 14:344

15. Gueye D, Senkoro K, Rumisha S. Baseline Monitoring and Evaluation of Integrated Disease Surveillance and Response in Tanzania. The Partners for Health Reformplus Project, Abt Associates Inc 2005; Bethesda, MD, U.S.A
16. Sahal N, Reintjes R, Mahgoub AE, Aro A.R. Assessment of core activities and supportive functions of the communicable diseases surveillance system in Khartoum state, Sudan for the years 2005-2007. PubMed Eastern Mediterranean Journal of Health 2010; 16(12):1204-1210.

17. Sow I, Alemu W, Nanyunji M, Duale S, Perry N, Gaturuku P. Trained district health personnel and the performance of integrated disease surveillance in the W.H.O African region. East African Journal of Public Health 2010; 7(1):16-19

18. Federal Ministry of Health (Nigeria). Report on the assessment of the Integrated Disease Surveillance and Response Implementation in Nigeria 2009; Abuja, Nigeria.

19. Mghamba JM, Mboera LE, Krekamo W, Senkoro KP, Rumisha SF, Shayo E. Challenges of implementing an IDSR strategy using the current health management information system in Tanzania. Tanzan. Health Res Bull. 2004; 6(2):57-63. PubMed

20. Epidemiology Division, Federal Ministry of Health (Nigeria). Report on the assessment of disease surveillance system, epidemic preparedness and response in $\mathrm{Ni}$ geria 2001; Abuja, Nigeria.

21. Centers for Disease Control and Prevention (CDC). Assessment of infectious disease surveillance-Uganda, Morb. Mortal Wkly Rep. 2000; 49(30):687-91. PubMed

22. Abubakar AA, Sambo MN, Idris SH, Sabitu K, Nguku P. Assessment of integrated disease surveillance and response strategy implementation in selected Local Government Areas of Kaduna state. Annals of Nigerian Medicine. 2013; 7(1):14-19

23. Bawa SB, Olumide EA, Umar U.S. The knowledge, attitude and practices of the reporting of notifiable diseases among health workers in Yobe State. Nigeria Afr. J. Med. Sc. 2003; 32(1):49-53.

24. Abubakar AA, Idris SH, Sabitu K, Shehu AU, Sambo MN. Emergency preparedness and capability to identify outbreaks: A case study of Sabon Gari Local Government Area, Kaduna state. Annals of Nigerian Medicine. 2010; 4(1):21-27

25. Bawa SB, Olumide EA. The effect of training on the reporting of notifiable diseases among health workers in Yobe State, Nigeria. Niger. Postgrad. Med. J 2005; 12(1):1-5. PubMed 